\title{
Sleep apnoea during upper respiratory infection and metabolic alkalosis in infancy
}

\author{
F A ABREU E SILVA, U M MACFADYEN, A WILliAMS, AND H SIMPSON \\ Department of Child Life and Health, University of Edinburgh, Royal Hospital for Sick Children, \\ Edinburgh, and Department of Child Health, University of Leicester
}

SUMmaRY Three to four hour polygraphic sleep studies were carried out in 10 infants, five with upper respiratory infection and five with metabolic alkalosis secondary to vomiting during and after recovery from illness. During upper respiratory infection, the main abnormality detected was brief $(>3<6$ seconds) or prolonged ( $>6$ seconds) attacks of obstructive apnoea. Other indices of apnoea were similar to recovery data. Gross body movements were also increased. In infants with metabolic alkalosis indices of central apnoea were significantly increased when compared with recovery or case control data. Prolonged ( $>15$ seconds) attacks of central apnoea and obstructive apnoea ( $>6$ seconds) were only observed during illness. Gross body movements and periodic breathing were also increased.

These findings suggest that the functional consequences of apparently 'mild' illnesses in young infants may be greater than is generally suspected and perhaps relevant to mechanism(s) of death in sudden infant death syndrome.

Most infants have minor symptoms at some time during the early weeks of life but recover uneventfully. Several investigators observed an increased frequency of such symptoms before death in victims of sudden infant death syndrome. ${ }^{1-4}$ Fifty nine per cent of the 145 victims of the syndrome studied by Stanton $e t$ al had recent symptoms, predominantly respiratory, compared with $16 \%$ of 154 controls. $^{5}$ The questions arise whether 'minor' illnesses trigger a fatal sequence of events in a predetermined group of infants with altered responsiveness or whether age and maturity increase susceptibility in all infants from which a subgroup succumbs. The nature and severity of naturally occurring stresses that cause minor symptoms have received little attention. We have investigated the cardiorespiratory effects of natural stresses (upper respiratory tract infection and metabolic alkalosis caused by vomiting) in normal infants in the age group at risk for sudden infant death syndrome. The infants were not considered at increased risk in other aspects.

\section{Patients and methods}

Two groups of infants were studied during and after recovery from symptoms-one group with upper respiratory infection and the other with recurrent vomiting.

\section{Groups studied.}

\section{Group 1: respiratory tract infections}

Five infants were studied during and after recovery from upper respiratory tract infection. Four were born at term after uncomplicated pregnancies and deliveries; the fifth was born at 29 weeks' gestation after premature rupture of the membranes. There were four boys and one girl, with a mean gestation of 38 weeks (range 29-41 weeks) and a mean birth weight of $2630 \mathrm{~g}$ (range 1290-3460 g). Mean chronological and postconceptional ages were 8 weeks (range 4-15 weeks) and 46 weeks (range 44-49 weeks), respectively, when initial studies were carried out. The mean interval between illness and recovery studies was 22 days (range 13-46 days). Initially, the infants had coryzal symptoms but were otherwise well. At follow up they were healthy and thriving. Mean rectal temperature was $36.9^{\circ} \mathrm{C}$ (range $36.4-37.5^{\circ} \mathrm{C}$ ) during infection and $36.8^{\circ} \mathrm{C}$ $\left(36 \cdot 5-37 \cdot 2^{\circ} \mathrm{C}\right)$ after recovery. There were no signs of respiratory distress on either occasion and on auscultation breath sounds were vesicular without 
accompaniments. Immunofluorescent studies of nasopharyngeal secretions confirmed respiratory syncytial virus infection in one infant.

\section{Group 2: recurrent vomiting}

Five infants with a history of recurrent vomiting of duration of four to 21 days were also studied before and after pyloromyotomy for congenital hypertrophic pyloric stenosis. They had been born after uncomplicated pregnancies and deliveries. All were boys, with a mean birth weight of $3270 \mathrm{~g}$ (range $2690-3770 \mathrm{~g}$ ) and a mean gestation of 39 weeks (range 36-40 weeks). Mean chronological and postconceptional ages were 5 weeks (3-7 weeks) and 44 weeks (39-47 weeks), respectively, when initial studies were carried out. The mean interval between studies was nine days and between surgery and follow up studies was seven days (range 3-11 days).

Pyloric stenosis was suspected on clinical grounds in each infant at the time of admission to hospital and confirmed by palpation of a pyloric tumour during a test feed. In each case the degree of dehydration was judged to be less than $5 \%$ of body weight and intravenous administration of fluid and electrolytes was not deemed necessary to correct fluid and electrolyte inbalance. Table 1 gives serum electrolytes and blood urea concentrations and acid base state in individual infants when initial studies were conducted. One infant, case 1 , was hypokalaemic, but otherwise electrolyte and blood urea values were remarkably normal. All infants showed moderate metabolic alkalosis. At follow up clinical recovery was apparently complete. Serum electrolyte and blood urea concentrations had become normal after treatment, and bottle feeding had been satisfactorily resumed in each case.

Infants in the above groups served as their own controls. In addition, five healthy, normal infants matched for age, sex, and postconceptional age were selected as a case control group for infants with recurrent vomiting because of the possibility that index infants had not fully recovered from the metabolic upset associated with recurrent vomiting at the time of follow up studies.

Monitoring procedures. These have been described previously. 6

Polygraphic sleep studies were carried out in hospital after the last evening feed, usually between 2300 and $0400 \mathrm{~h}$. For follow up studies infants were re-admitted on the preceding afternoon. They were monitored in a dimly lit side room off the main ward, especially equipped for sleep studies. Ambient temperature ranged from $22-25^{\circ} \mathrm{C}$. Electrodes were placed in position when the infant had settled after a feed, and nasal thermocouples were applied during periods of quiet sleep. Each infant, lightly clothed and unrestrained, was observed constantly and body movements and interventions recorded on polygraphic paper. Electroencephalogram, electro-oculogram, electromyogram, electrocardiogram, chest and abdominal movements, and nasal airflow were recorded on a Mingograf recorder at a paper speed of $10 \mathrm{~mm}$ per second. Sections of recording in each sleep state were also recorded at a rate of $100 \mathrm{~mm} / \mathrm{second}$ to observe electroencephalogram changes more closely. Permanent records were thus available for electroencephalogram, electro-oculogram, electromyogram, electrocardiogram, nasal airflow, and chest and abdominal movements.

Data analysis. Each 30 second period (one epoch) of the record was analysed visually and sleep state coded according to the criteria of Anders et $\mathrm{al}^{7}$ and those of Rechtschaffen and Kales. ${ }^{8}$ The age range of the subjects was such that in some infants the transition between perinatal and 'infantile' sleep pattern ${ }^{9}$ might not have been completed. Individual proportions of the electroencephalogram frequencies and amplitudes during the sleep stages were used rather than absolute limits. Respiration, the variable under study, was omitted from the criteria

Table 1 Serum electrolytes and blood urea concentrations and acid base states of infants with pyloric stenosis

\begin{tabular}{|c|c|c|c|c|c|c|c|c|}
\hline \multirow{2}{*}{$\begin{array}{l}\text { Case } \\
\text { No }\end{array}$} & \multicolumn{3}{|c|}{ Serum electrolytes ( $\mathrm{mmol} / \mathrm{l}$ ) } & \multirow{2}{*}{$\begin{array}{l}\text { Blood } \\
\text { urea } \\
\text { (mmol/l) }\end{array}$} & \multicolumn{4}{|c|}{ Acid base state } \\
\hline & Sodium & Potassium & Chloride & & $p H$ & $\begin{array}{l}\text { Carbon } \\
\text { dioxide } \\
\text { tension } \\
(\mathrm{kPa})\end{array}$ & $\begin{array}{l}\text { Subtype } \\
\text { bicarbonate } \\
\text { ion } \\
(\mathrm{mmol} / \mathrm{l})\end{array}$ & $\begin{array}{l}\text { Base excess } \\
\text { (mmolll) }\end{array}$ \\
\hline 1 & 138 & $2 \cdot 4$ & - & $5 \cdot 0$ & 7.53 & $7 \cdot 35$ & $40 \cdot 6$ & $+21 \cdot 6$ \\
\hline 2 & 138 & $3 \cdot 7$ & 94 & $3 \cdot 3$ & 7.49 & 5.87 & $35 \cdot 0$ & $+11 \cdot 0$ \\
\hline 3 & 136 & $3 \cdot 6$ & 86 & 5.6 & 7.49 & $5 \cdot 70$ & $34 \cdot 0$ & +9.5 \\
\hline 4 & 139 & $4 \cdot 3$ & 98 & 4.4 & $7 \cdot 48$ & $5 \cdot 25$ & $29 \cdot 3$ & +6.6 \\
\hline 5 & 138 & $3 \cdot 4$ & 96 & $3 \cdot 7$ & $7 \cdot 50$ & $5 \cdot 57$ & $30 \cdot 9$ & $+8 \cdot 8$ \\
\hline
\end{tabular}


of the sleep stages. These were identified as quiet sleep, active sleep, and indeterminate sleep.

The respiration rate and heart rate were counted during the fourth, middle, and last minutes of continuous sleep for quiet and active sleep. Mean respiration rate and heart rate for each sleep state was then computed for each patient during and after recovery from illness and for each control infant. Central apnoeic pauses were defined as periods when chest and abdominal movements were absent and airflow at the nostrils had ceased for at least six seconds. Obstructive apnoea refers to periods during which there was stopping of airflow at the nostrils and continuing (often exaggerated) movements of the chest or abdomen, or both, not begun by gross body movements detected by direct observation or electromyogram recording. This latter proviso ensured that episodes of apparent obstructive apnoea begun by movement ${ }^{10}$ were excluded from analysis. The occurrence of prolonged (>15 seconds) attacks of central apnoea ${ }^{11}$ and brief $\left(>3\right.$ and $<6$ seconds) or prolonged $(>6)$ attacks $^{12}$ were also noted. Indices of apnoea were assessed for central apnoeic pauses greater than six seconds. Apnoea index was defined as the duration of attacks of apnoea (seconds) during a given sleep state divided by the total duration of that sleep state expressed as a percentage. Rate of attacks of apnoea was the number of attacks of apnoea in each 100 seconds of a sleep state, and apnoea per cent was the percentage of epochs during which at least one apnoeic pause was begun. For each sleep state the mean duration of apnoeic pauses was calculated and the attack of apnoea of longest duration noted. These variables were computed for each sleep state and total sleep time. The percentage of time in each sleep state was also noted.

The occurrence and duration of periodic breathing, defined by Parmalee et al as two attacks of apnoea of three seconds or more within 20 seconds of each other, ${ }^{13}$ and gross body movements were computed in relation to sleep state and total sleep time.

Statistical analysis. The Wilcoxon matched pairs signed rank test was applied to the results obtained during and after recovery from illness in both groups of infants. The Mann-Whitney U test was applied to results obtained for infants with metabolic alkalosis and their matched case controls.

\section{Results}

Group 1: respiratory tract infections. Table 2 gives the results for apnoea variables, per cent sleep, respiration rate, and heart rate in relation to sleep phase in the five infants during and after recovery from upper respiratory tract infection. With the exception of respiration rate, which was slightly but significantly increased after recovery, no significant differences were observed between corresponding

Table 2 Apnoea variables, per cent sleep, and respiration and heart rates in five infants during and after recovery from upper respiratory tract infection. Values are mean (SE)

\begin{tabular}{|c|c|c|c|}
\hline & $\begin{array}{l}\text { Sleep } \\
\text { phase }\end{array}$ & $\begin{array}{l}\text { During } \\
\text { recovery }\end{array}$ & $\begin{array}{l}\text { After } \\
\text { recovery }\end{array}$ \\
\hline \multirow[t]{4}{*}{ Apnoea index } & Active & $0.24(0.07)$ & $0.69(0.42)$ \\
\hline & Quiet & $1 \cdot 10(0.46)$ & $0.67(0 \cdot 18)$ \\
\hline & Indeterminate & $0.33(0.20)$ & $1.11(0.49)$ \\
\hline & Total & $0.59(0.24)$ & $0.68(0.23)$ \\
\hline \multirow[t]{4}{*}{ Apnoea attack rate } & Active & $0.04(0.01)$ & $0.09(0.04)$ \\
\hline & Quiet & $0 \cdot 14(0 \cdot 06)$ & $0.08(0.02)$ \\
\hline & Indeterminate & $0.06(0.04)$ & $0.15(0.07)$ \\
\hline & Total & $0.08(0.03)$ & $0.13(0.05)$ \\
\hline \multirow{4}{*}{$\begin{array}{l}\text { Attack of longest } \\
\text { duration (sec) }\end{array}$} & Active & $5 \cdot 20(1 \cdot 32)$ & $6.20(1.83)$ \\
\hline & Quiet & $5 \cdot 84(2 \cdot 54)$ & $7 \cdot 68(2 \cdot 16)$ \\
\hline & Indeterminate & $2.80(1.72)$ & $4.62(1.89)$ \\
\hline & Total & $7 \cdot 22(2 \cdot 09)$ & $7 \cdot 78(2 \cdot 16)$ \\
\hline \multirow{4}{*}{$\begin{array}{l}\text { Mean duration of } \\
\text { attack of apnoea } \\
\text { (sec) }\end{array}$} & Active & $5.09(1.28)$ & $5.62(1.53)$ \\
\hline & Quiet & $4.95(2 \cdot 14)$ & $5.63(1.72)$ \\
\hline & Indeterminate & $2.67(1.63)$ & $4.30(1.76)$ \\
\hline & Total & $5.97(1.62)$ & $6.05(1.60)$ \\
\hline \multirow[t]{4}{*}{ Apnoea per cent } & Active & $1.15(0.36)$ & $2.63(1.31)$ \\
\hline & Quiet & $3.59(1.58)$ & $2.63(0.70)$ \\
\hline & Indeterminate & $1.51(0.93)$ & $4.80(2.09)$ \\
\hline & Total & $2 \cdot 06(0.79)$ & $2 \cdot 61(0.76)$ \\
\hline \multirow[t]{2}{*}{ Sleep per cent } & Active & $42 \cdot 20(6 \cdot 58)$ & $39.80(5.89)$ \\
\hline & Quiet & $41 \cdot 80(5 \cdot 50)$ & $52.40(6.95)$ \\
\hline \multirow[t]{2}{*}{ Respiration rate } & Active & $38 \cdot 25(3 \cdot 32)$ & $36.95(4.68)$ \\
\hline & Quiet & $32 \cdot 04(2 \cdot 62)$ & $34.20(3 \cdot 84)^{*}$ \\
\hline \multirow{2}{*}{ Heart rate } & Active & $132 \cdot 00(5 \cdot 74)$ & $134.90(5 \cdot 04)$ \\
\hline & Quiet & $127 \cdot 74(4 \cdot 79)$ & $131 \cdot 32(5 \cdot 29)$ \\
\hline
\end{tabular}

${ }^{*} \mathrm{p}<0 \cdot 05$.

Table 3 Gross body movements and periodic breathing in relation to sleep phase in five infants during and after recovery from upper respiratory infection. Values are mean (SE)

\begin{tabular}{|c|c|c|c|}
\hline & $\begin{array}{l}\text { Sleep } \\
\text { phase }\end{array}$ & $\begin{array}{l}\text { During } \\
\text { recovery }\end{array}$ & $\begin{array}{l}\text { After } \\
\text { recovery }\end{array}$ \\
\hline \multicolumn{4}{|l|}{ Body movements: } \\
\hline \multirow{4}{*}{$\begin{array}{l}\text { Total duration } \\
(\mathrm{min} / 100 \mathrm{~min} \text { sleep })\end{array}$} & Active & $5.68(1.99)$ & $1.48(0 \cdot 31)$ \\
\hline & Quiet & $0.68(0.34)$ & $0.63(0.16)$ \\
\hline & Indeterminate & $58.21(9.28)$ & $39 \cdot 10(10 \cdot 77)$ \\
\hline & Total & $12 \cdot 80(2.44)$ & $4.01(0.96)$ \\
\hline \multirow[t]{4}{*}{ No/100 min sleep } & Active & $28(10 \cdot 18)$ & $7(1.59)$ \\
\hline & Quiet & $4(2 \cdot 13)$ & $5(1.88)$ \\
\hline & Indeterminate & $148(14 \cdot 87)$ & $87(14 \cdot 11)$ \\
\hline & Total & $38(6 \cdot 71)$ & $12(2.46)^{*}$ \\
\hline \multicolumn{4}{|l|}{ Periodic breathing: } \\
\hline \multirow{4}{*}{$\begin{array}{l}\text { Total duration } \\
(\mathrm{min} / 100 \mathrm{~min} \text { sleep) }\end{array}$} & Active & $0 \cdot 38(0 \cdot 27)$ & $1.31(0.89)$ \\
\hline & Quiet & $1.22(0.77)$ & $0.83(0.28)$ \\
\hline & Indeterminate & $0.59(0.45)$ & $0.58(0.58)$ \\
\hline & Total & $0.75(0.46)$ & $1 \cdot 12(0.54)$ \\
\hline \multirow{4}{*}{$\mathrm{No} / 100 \mathrm{~min}$ sleep } & Active & $1(0.77)$ & $4(2.91)$ \\
\hline & Quiet & $3(1.84)$ & $3(1.02)$ \\
\hline & Indeterminate & $2(0.73)$ & $2(2 \cdot 20)$ \\
\hline & Total & $2(1 \cdot 11)$ & $4(1.81)$ \\
\hline
\end{tabular}

${ }^{*} \mathrm{p}<0.05$. 
variables in either active or quiet sleep. No infant had attacks of central apnoea exceeding 15 seconds. Three infants had brief ( $>3$ and $<6$ seconds) or prolonged ( $>6$ seconds) attacks of obstructive apnoea in active sleep during the course of infection, with resolution on clinical recovery. In no case did the maximum duration of an attack of obstructive apnoea exceed 10 seconds.

Table 3 gives the results for gross body movements and periodic breathing. The number and duration of movements for each 100 minutes of total sleep time was significantly increased during infection; no differences were observed in the amount of periodic breathing present.

Group 2: recurrent vomiting. Table 4 gives the results for apnoea variables, per cent sleep, respiration rate, and heart rate in relation to sleep state in the five infants during and after recovery from pyloric stenosis and in their matched controls without antecedent vomiting. Apnoea index, rate of attacks of apnoea, and apnoea per cent were significantly increased during illness, usually in both active and quite sleep states when compared with recovery or matched control data. Similarly, the mean and longest duration of attacks of apnoea were increased during illness. Two infants had prolonged ( $>15$ seconds) attacks of central apnoea in both active sleep and quiet sleep (cases 1 and 5). The proportion of time spent in each sleep stage was comparable during and after illness. Respiration and heart rates were significantly lower in quiet sleep during illness than after recovery; respiration rate was reduced when compared with matched controls in both active and quiet sleep. Four infants with vomiting had prolonged ( $>6$ seconds) attacks of obstructive apnoea in active sleep, with resolution on recovery. None of the matched control infants had either brief or prolonged attacks of obstructive apnoea.

Table 5 gives results for gross body movements and periodic breathing before and after recovery in index cases and also in matched control infants. The increase in body movements when symptoms were present did not reach significance when compared with controls, but the number of episodes and the total duration of periodic breathing were increased $(p=0 \cdot 06)$. Failure to reach significance in comparisons of index cases and controls is a reflection of the paucity of data available for non-parametric statistical comparisons. The Figure presents observations on periodic breathing in individual infants and illustrates the wide difference between illness and recovery data.

Table 4 Apnoea variables, per cent sleep, and respiration and heart rates in relation to sleep phase in five infants with recurrent vomiting and their matched case controls. Values are mean (SE)

\begin{tabular}{|c|c|c|c|c|}
\hline & \multirow{2}{*}{$\begin{array}{l}\text { Sleep } \\
\text { phase }\end{array}$} & \multicolumn{2}{|c|}{ Infants with vomiting } & \multirow[t]{2}{*}{ Controls } \\
\hline & & $\begin{array}{l}\text { During } \\
\text { recovery }\end{array}$ & $\begin{array}{l}\text { After } \\
\text { recovery }\end{array}$ & \\
\hline \multirow[t]{4}{*}{ Apnoea index } & Active & $7.00(2.48)$ & $0.99(0.52)^{*}$ & $0.67(0.43)^{*}$ \\
\hline & Quiet & $8.90(5 \cdot 17)$ & $0.91(0.45)^{*}$ & $0.65(0.27)^{*}$ \\
\hline & Indeterminate & $9 \cdot 36(4 \cdot 23)$ & $2.57(0.96)^{*}$ & $0.69(0.44)$ \\
\hline & Total & $7 \cdot 56(3 \cdot 18)$ & $1.13(0.56)^{*}$ & $0.59(0.26)^{*}$ \\
\hline \multirow[t]{4}{*}{ Apnoea attack rate } & Active & $0.87(0.29)$ & $0.13(0 \cdot 07)^{*}$ & $0.08(0.04)^{*}$ \\
\hline & Quiet & $1.05(0.62)$ & $0.13(0.06)^{*}$ & $0 \cdot 08(0 \cdot 04)$ \\
\hline & Indeterminate & $1.05(0.47)$ & $0.31(0.11)$ & $0.09(0.06)$ \\
\hline & Total & $0.90(0.37)$ & $0.15(0.07)^{*}$ & $0.07(0.03)^{*}$ \\
\hline \multirow{4}{*}{$\begin{array}{l}\text { Attack of longest } \\
\text { duration (sec) }\end{array}$} & Active & $13.30(1.37)$ & $7 \cdot 38(3 \cdot 15)$ & $6.38(1.85)$ \\
\hline & Quiet & $13 \cdot 02(0 \cdot 88)$ & $7.88(0.46)^{*}$ & $5.94(2.59)^{*}$ \\
\hline & Indeterminate & $9 \cdot 14(2 \cdot 49)$ & $8 \cdot 04(2 \cdot 13)$ & $4 \cdot 18(1.72)$ \\
\hline & Total & $14.82(0 \cdot 58)$ & $9.66(1.03)^{*}$ & $7 \cdot 38(2 \cdot 12)^{*}$ \\
\hline \multirow{4}{*}{$\begin{array}{l}\text { Mean duration of } \\
\text { apnoea }(\mathrm{sec})\end{array}$} & Active & $7.95(0.24)$ & $7 \cdot 33(0 \cdot 32)$ & $5.78(1.55)$ \\
\hline & Quiet & $9.48(0.91)$ & $7 \cdot 03(0 \cdot 26)^{*}$ & $5 \cdot 02(2 \cdot 13)$ \\
\hline & Indeterminate & $6.87(1.75)$ & $6.65(1.67)$ & $4 \cdot 18(1.72)$ \\
\hline & Total & $8.42(0.18)$ & $7 \cdot 37(0 \cdot 29)$ & $6.07(1.61)$ \\
\hline \multirow[t]{4}{*}{ Apnoea per cent } & Active & $21 \cdot 28(6 \cdot 34)$ & $3.67(1.83)^{*}$ & $2.41(1.34)^{*}$ \\
\hline & Quiet & $25 \cdot 51(14 \cdot 22)$ & $3.34(1.42)^{*}$ & $2.29(0.99)$ \\
\hline & Indeterminate & $27 \cdot 36(11 \cdot 58)$ & $8.91(3.19)$ & $2.86(1.69)$ \\
\hline & Total & $22 \cdot 14(8 \cdot 35)$ & $4.08(1.64)^{*}$ & $2 \cdot 15(0 \cdot 81)^{*}$ \\
\hline \multirow[t]{2}{*}{ Sleep per cent } & Active & $50 \cdot 20(2.63)$ & $46 \cdot 60(2 \cdot 50)$ & $45.60(5.49)$ \\
\hline & Quiet & $38.60(5.07)$ & $42 \cdot 00(3 \cdot 70)$ & $44 \cdot 20(6 \cdot 76)$ \\
\hline \multirow[t]{2}{*}{ Respiration rate } & Active & $25 \cdot 60(1 \cdot 11)$ & $31 \cdot 40(2 \cdot 70)$ & $37.60(3.00)^{*}$ \\
\hline & Quiet & $22.50(1.76)$ & $27.20(1.50)^{*}$ & $39.40(4 \cdot 12)^{*}$ \\
\hline \multirow[t]{2}{*}{ Heart rate } & Active & $123.40(6.63)$ & $129.60(5.94)$ & $125 \cdot 10(8 \cdot 00)$ \\
\hline & Quiet & $115 \cdot 20(5 \cdot 73)$ & $126 \cdot 50(4 \cdot 58)^{*}$ & $120 \cdot 70(7 \cdot 23)$ \\
\hline
\end{tabular}

${ }^{*} \mathrm{p}<0 \cdot 05$. 
1060 Abreu E Silva, MacFadyen, Williams, and Simpson

Table 5 Gross body movements and periodic breathing in relation to sleep phase in five infants during and after recovery from recurrent vomiting and their matched case controls. Values are mean (SE)

\begin{tabular}{|c|c|c|c|c|}
\hline & \multirow{2}{*}{$\begin{array}{l}\text { Sleep } \\
\text { phase }\end{array}$} & \multicolumn{2}{|c|}{ Infants with vomiting } & \multirow[t]{2}{*}{ Controls } \\
\hline & & $\begin{array}{l}\text { During } \\
\text { recovery }\end{array}$ & $\begin{array}{l}\text { After } \\
\text { recovery }\end{array}$ & \\
\hline \multicolumn{5}{|l|}{ Body movements: } \\
\hline \multirow{4}{*}{$\begin{array}{l}\text { Total duration } \\
(\mathrm{min} / 100 \text { sleep })\end{array}$} & Active & $4.28(0.83)$ & $4 \cdot 36(0.52)$ & $6 \cdot 23(2 \cdot 32)$ \\
\hline & Ouiet & $1.33(0.45)$ & $0.84(0.32)$ & $1 \cdot 19(0.56)$ \\
\hline & Indeterminate & $56.27(11.34)$ & $43.41(3.92)$ & $36.76(11.57)$ \\
\hline & Total & $8.56(2.20)$ & $7.78(1.77)$ & $6.80(1.25)$ \\
\hline \multirow{4}{*}{ Number/100 min sleep } & Active & $24(5.46)$ & $25(2 \cdot 13)$ & $24(7.72)$ \\
\hline & Quiet & $11(3 \cdot 20)$ & $5(4 \cdot 64)$ & $12(5 \cdot 56)$ \\
\hline & Indeterminate & $275(128 \cdot 38)$ & $120 \cdot(9 \cdot 75)$ & $77(24 \cdot 39)$ \\
\hline & Total & $35(10 \cdot 18)$ & $29(5.119)$ & $23(4 \cdot(17)$ \\
\hline \multicolumn{5}{|l|}{ Periodic breathing: } \\
\hline Total duration & Active & $18.91(7.43)$ & $1.93(1.14)$ & $0.62(0.50)$ \\
\hline \multirow{3}{*}{$(\mathrm{min} / 100 \mathrm{~min}$ sleep $)$} & Quiet & $21 \cdot 28(12 \cdot 58)$ & $0.84(0.83)$ & $0.56(0.25)$ \\
\hline & Indeterminate & $12 \cdot 41(6 \cdot 14)$ & $1.46(1 \cdot 16)$ & $0 \cdot(0)(0 \cdot(0))$ \\
\hline & Total & $15.65(8.01)$ & $1.31(0.64)^{*}$ & $0.62(0.25)$ \\
\hline \multirow[t]{4}{*}{$\mathrm{No} / 100 \mathrm{~min}$ sleep } & Active & $25(7 \cdot(16)$ & $5(2 \cdot 4(1)$ & $2(1.19)$ \\
\hline & Quiet & $14(8.46)$ & $1(1 \cdot(0))$ & $2(0 \cdot 85)$ \\
\hline & Indeterminate & $23(10 \cdot 12)$ & $6(4.49)$ & $0(0 \cdot 00)$ \\
\hline & Total & $20(7 \cdot 48)$ & $3(1.26)^{*}$ & $2(0 \cdot 65)$ \\
\hline
\end{tabular}

${ }^{*} \mathrm{p}=0.06$.

Sleep phase

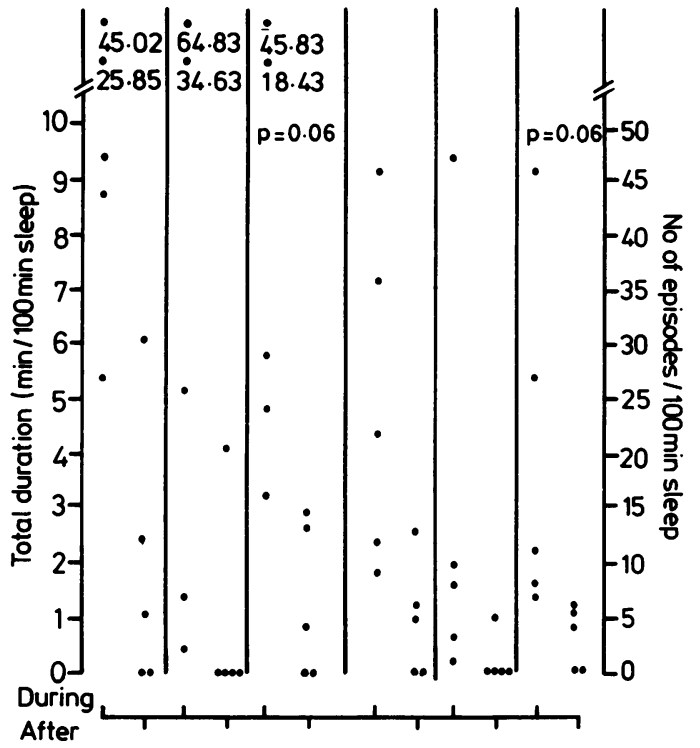

Figure No of episodes and total duration of periodic breathing during sleep in five infants during and after recovery from recurrent vomiting.

\section{Discussion}

These results present an opportunity to comment on the effects of natural stresses (upper respiratory infection and metabolic alkalosis) on breathing during sleep in infants, at an age when the incidence of sudden infant death syndrome is greatest.
An association between upper respiratory tract infection and sudden infant death syndrome is well documented by epidemiological and pathological studies. ${ }^{514-17}$ Several authors have reported that prolonged attacks of apnoea occur more often during upper respiratory infection in infants thought to be at increased risk for the syndrome. ${ }^{18-20}$ In the present study no differences were observed between indices of apnoea during and after recovery from infection. Prolonged attacks of central apnoea ( $>15$ seconds) were not observed, but brief attacks of obstructive apnoea were present in three infants in active sleep, which scarcely affected heart rate. Obstructive attacks exceeding six seconds were accompanied by bradycardia. None of the full term infants studied was thought to be at increased risk for sudden infant death syndrome on epidemiological grounds. ${ }^{21}$

In view of the small number of cases studied it would be misleading to generalise on the likelihood of prolonged or severe attacks of apnoea in such cases. In a retrospective study of hospital charts of 274 infants under 6 months of age with proven respiratory syncytial virus infection Bruhn et al reported an association between respiratory infection caused by this virus and prolonged attacks of apnoea. ${ }^{22}$ The association was strongest during the first months of life and in infants born prematurely. Mitchell et al reported a prospective study of the frequency and severity of attacks of apnoea in respiratory tract infections in infancy. ${ }^{23}$ In nine infants with upper respiratory tract infection there were 121 attacks of apnoea exceeding 10 seconds (assessed by impedance pneumography), and in $8 \%$ 


\section{Sleep apnoea during upper respiratory}

their duration exceeded 20 seconds. Severe bradycardia was sometimes unrelated to central apnoea. It is possible (perhaps probable) that these episodes of bradycardia resulted from attacks of obstructive apnoea not detectable by the methods they employed.

Gould et al described the effects of upper respiratory tract infection on twins studied polygraphically in the early months of life during two to three hour interfeed periods of sleep. ${ }^{24}$ Infants with colds exhibited alterations specific for sleep state in sleep apnoea. At postconceptional ages of 40,44 , and 48 weeks the number of respiratory pauses of duration of 2.0 to 4.9 seconds and of 5.0 to 5.9 seconds for each 100 minutes of state were decreased during active and indeterminate sleep. This phenomenon did not occur at a postconceptional age of 52 weeks, suggesting that it had been modified by maturation. These authors hypothesised that the response described during the early weeks after birth was adaptive but for infants at risk for sudden infant death syndrome such adaptation could be overwhelmed, resulting in increased attacks of apnoea and sometimes sudden infant death. In our cases gross body movements were increased during the course of upper respiratory infection in relation to total sleep time (Table 3) and no differences were observed between infection and recovery values during quiet sleep. Thus arousals (as indicated by gross body movements) were increased generally and were unaffected during quiet sleep by upper respiratory infection.

In the infants with pyloric stenosis apnoea variables were significantly increased in both active and quiet sleep. Respiration and heart rates decreased in quiet sleep during the acute phase of illness when each infant had moderate metabolic alkalosis. Metabolic alkalosis of varying degree is nearly always present in such infants before surgical treatment. ${ }^{25}$ In this situation the metabolic stimulus to breathing is reduced and any resulting abnormality in breathing pattern should be most obvious in quiet sleep. ${ }^{26}$ Prolonged and potentially hazardous attacks of central apnoea might then result from loss of stimulus to wakefulness and/or a defect in metabolic control affecting central or peripheral chemoreceptor mechanisms. We observed prolonged attacks of central apnoea exceeding 15 seconds in two infants in both active and quiet sleep. In both infants gross body movements were increased during illness not only in relation to total sleep time but also quiet sleep, suggesting that arousal mechanisms were intact. Four of the five infants with pyloric stenosis also had attacks of obstructive apnoea during active sleep, perhaps due to loss of upper airway tone in that sleep state, possibly exaggerated by depletion infection and metabolic alkalosis in infancy 1061

of intracellular potassium. Prolonged attacks of either central apnoea or obstructive apnoea were not observed after clinical recovery or in the matched control infants. In a previous report we did not detect these abnormalities in 11 healthy infants free of symptoms with a mean age of 48.6 weeks (range 38-63 weeks) studied on 31 occasions in the early months of life. ${ }^{27}$ Thus, despite the relative paucity of control data in the present study, it seems reasonable to ascribe our findings to the effects of 'minor' illness.

Whether infants exhibiting the breathing patterns observed in upper respiratory infection and pyloric stenosis are at increased risk for sudden infant death syndrome is not known. We have observed infants with upper respiratory infection, severe metabolic alkalosis, and congenital stridor presenting with 'near miss' for episodes of the syndrome, who exhibited in even greater degree the respiratory patterns described. One such infant presented with both upper respiratory tract infection and vomiting. Pyloric stenosis was suspected clinically and confirmed at operation. It is conceivable that the summation of such stresses, perhaps of minor significance individually, influences respiratory control to produce abnormalities of breathing patterns of sufficient severity in some infants to begin the sequence that culminates in a 'near miss' episode or even sudden death. It may be unnecessary to postulate a fundamental defect in respiratory or other control mechanisms in these circumstances. Our findings support the idea that infective and metabolic stresses, manifest as 'minor' illnesses in young infants, may have respiratory consequences that are potentially profound.

We thank the parents, who allowed us to study their infants, and Mrs P Walker, who typed the manuscript.

This study was supported by the Foundation for the Study of Infant Deaths (grant no 28/HS/78).

\section{References}

${ }^{1}$ Emery JL, Crowley EM. Clinical histories of infants reported to coroner as cases of sudden infant death. $\mathrm{Br}$ Med $J$ 1956;ii: 1518-21.

2 Carpenter RG, Shaddick CW. Role of infection, suffocation and bottle feeding in cot death. British Journal of Preventative and Social Medicine 1965;19:1-7.

${ }^{3}$ Froggatt P. Epidemiology aspects of Northern Ireland study. In: Bergman AB, Beckwith J, Ray CG, eds. Sudden infant death syndrome. Seattle: University of Washington Press, 1970:32-6.

4 Cameron JM, Watson E. Sudden death in infancy in Inner North London. J Pathol 1974;117:55-61.

${ }^{5}$ Stanton AH, Downham MAPS, Oakley JR, Emery JL, Knowelden $J$. Terminal symptoms in children dying suddenly and unexpectedly at home. Br Med J 1978;ii:1249-51.

- Abreu e Silva FA, Brezinova V. Simpson H. Sleep apnoea in acute bronchiolitis. Arch Dis Child 1982;57:467-72. 
1062 Abreu E Silva, MacFadyen, Williams, and Simpson

7 Anders T, Emde R, Parmalee A. A manual of standardized terminology and criteria for scoring of states of sleep and wakefulness in newborn infants. Los Angeles: UCLA Brain Information Service, BRI Publications Office, 1971.

${ }^{8}$ Rechtschaffen A. Kales A. A manual of standard terminology, techniques, and scoring system for states of human subjects. Washington: National Institute of Health, 1968. (No 204.)

${ }^{9}$ Ellingson RV. EEG of premature and full term newborn. In: Klass DW, Daly DD, eds. Current practice of clinical electroencephalography. New York: Raven Press, 1979:149-77.

10 Van Someren V, Stothers JK. A critical dissection of obstructive apnea in the human infant. Pediatrics 1983;71:721-5.

1 Steinschneider A. Prolonged apnea and sudden infant death syndrome: clinical and laboratory observations. Pediatrics 1972; 50:646-54

12 Guilleminault C, Ariagno R, Korobkin R, et al. Mixed and obstructive sleep apnea and near miss for sudden infant death syndrome. 2. Comparison of near miss and normal control infants by age. Pediatrics 1979;64:882-91.

13 Parmalee AH, Stern E, Harris MA. Maturation of respiration in premature and young infants. Neuropadiatrie 1972;3:294-304.

14 Carpenter RG, Gardner A, Pusall E, McWeeney PM, Emery $\mathrm{JL}$. Identification of some infants at immediate risk of dying unexpectedly and justifying intensive study. Lancet 1979;ii: 343-6.

15 Werne J. Post mortem evidence of acute infection in unexpected death in infancy. Am J Pathol 1942;18:759-69.

16 Bowden KM, French EL. Unexpected death in infants and young children. Med J Aust 1951:1:925-33.

17 Williams AL. Tracheobronchitis and sudden infant death syndrome. Pathology 1980;12:73-8.
${ }^{18}$ Steinschneider A. Nasopharyngitis and prolonged sleep apnoea. Pediatrics 1975;56:967-71.

19 Brady JP, Ariagno RL, Watts JL, Goldman SL, Dumpit BS. Apnea, hypoxemia and aborted sudden infant death syndrome. Pediatrics 1978;62:686-91.

20) Stevens LH. Sudden unexplained death in infancy: observations on a natural mechanism of adaption of the face down position. Am J Dis Child 1965;110:243-7.

21 Carpenter RG, Gardner A, McWeeny PM, Emery JL. Multistage scoring system for identifying infants at risk of unexpected death. Arch Dis Child 1977;52:606-12.

22 Bruhn FW, Mokrohisky ST, McIntosh K. Apnea associated with respiratory syncytial virus infection in young infants. $J$ Pediatr 1977;90:382-6.

${ }^{23}$ Mitchell I, Barclay RPC, Railton R, Fisher J, Conely J. Frequency and severity of apnoea in lower respiratory tract infection in infancy. Arch Dis Child 1983;58:497-9.

${ }^{24}$ Gould JB, Lee AFS, Cook P, Morelock S. Apnea and sleep state in infants with nasopharyngitis. Pediatrics 1980;65:713-7.

${ }^{25}$ Degn JK, Wamberg K, Engel K, Kildberg P. Metabolic alkalosis in obstructive vomiting. Acta Paediatr Scand 1974;63:537-48.

${ }^{26}$ Phillipson EA. Control of breathing during sleep. Am Rev Respir Dis 1978;118:909-39.

27 Abreu e Silva FA. MacFadyen UM, Williams A, Simpson H. Sleep apnoea in infancy. $J R$ Soc Med 1985;78:1005-8.

Correspondence to Professor H Simpson, Department of Child Health, Clinical Sciences Building, Leicester Royal Infirmary, PO Box 65, Leicester LE2 7LX, England.

Received 24 June 1986 